Session 2533

\title{
Energy Systems and Conversion - Course and Content
}

\author{
Peter Idowu, \\ Pennsylvania State Harrisburg. \\ 777 W. Harrisburg Pike, Middletown, PA 17057
}

\begin{abstract}
The energy conversion course is traditionally included in the requirements for an undergraduate degree in electrical engineering. The course typically covers topics in transformers and classical rotating machinery. As the competition becomes more intense for the limited undergraduate credit-hours this practice has been on the decline. As a result, there is a growing population of electrical engineers in practice with a very limited knowledge of the theory and application of energy conversion devices. This paper highlights a required undergraduate course on energy systems and conversion for electrical engineering (EE) students at Penn State University Harrisburg. The new course format adds components that are not typically included in the students' exposure to the subject. It guides students to explore various energy sources, conversion technologies, and highlights economic, environmental, sustainability, ethical, health and safety, social, and political issues in energy use.
\end{abstract}

\section{Introduction}

Many electrical engineering (EE) programs traditionally include an energy conversion course in the program requirements for the undergraduate degree. This required course typically covers topics in transformers and classical rotating machinery. The practice has been on the decline over the last decade. It is now no longer unusual to have EE graduates enrolled in (for instance,) a graduate power systems control class without a thorough knowledge of three-phase generation systems, or employed as circuit designers for adjustable speed drives for induction motors without ever sitting through a class on the theory of electric machines. The typical EE program never saw the need to revise the curriculum and integrate emerging technologies that made possible the appeal of alternative energy systems.

This paper highlights a required undergraduate course in energy systems and conversion for EE students at Penn State University - Harrisburg. While the new course format reflects some of the contents that exist in a few programs ${ }^{1}$, it adds other components that are not usually included in the students' exposure to the subject. It guides students to explore various energy sources, conversion technologies, and highlights economic, environmental, sustainability, ethical, health and safety, social, and political issues in energy use. This is done through the use of group projects and reports that directly focus on policies and politics of energy exploitation and use, review of newspaper stories focusing on energy, and by collating and organizing a wealth of 
information available on the worldwide web. This has aided the students in recognizing the dominant role that non-engineering entities -- policy makers, etc., play in the success or failure of any of the energy technologies. In addition to the required 'static' course textbook, the lectures take advantage of the wealth of up-to-date resources on energy research, energy use, illustrations, animations, and databases that are available on the worldwide web. Furthermore, cutting edge research is regularly featured in the classroom experience by pulling up and working through examples in current journal publications.

\section{Course Objectives}

The objective of this course is to provide students at the upper undergraduate level an overview of available energy alternatives, and complete understanding of the fundamental theory of operation and system models for major energy conversion devices. The topics covered furnish students the tools to assess the viability of various energy options, their applications, and their impact on the environment. Various forms of raw energy sources used in powering conventional electric generating plants such as coal, natural gas, oil, and uranium are studied, along with worldwide distribution and reserves. The analytical methods for determining quantities of energy that can be extracted from the wind, waterfalls, and solar energy sources using practical devices are presented in the course as well as in various case studies. The state of the art in energy storage technology and its impact on electrical vehicle range are also covered in the first half of the semester.

The second half of the semester is devoted to theoretical fundamentals and applications of major energy conversion devices. Lessons on magnetic circuits cover the electrical circuit model and analog for studying energy transfer involving magnetic systems. A direct application link to the power transformer is established; and later to rotating machines in general. A breakdown of the course content for a sixteen-week semester is shown in Table 1.

Students enrolled in this course are expected to have completed basic courses in calculus (Calculus I \& II), Physics, AC-DC Circuit analysis.

\section{Resources}

Textbooks and other sources used in the course are listed in the reference section ${ }^{1-8}$. Materials from peer-reviewed journals are vital in connecting students to cutting edge information, applications and current trends in energy exploitation.

Computer simulation programs are used in the course for modeling and clarifying some concepts in energy use. MATLAB ${ }^{\odot}$ functions are used for developing regression models for predicting growth (population, energy use, etc.). MATLAB-SimPowerSystems ${ }^{\circledR}$ is used for modeling AC and DC machines, and to demonstrate their performance characteristics.

PowerWorld ${ }^{\odot 10}$ is used to illustrate computational challenges in a modern power transmission system. The animation model illustrating the solution of the economic dispatch problem offers a 
very useful insight into the challenges of power wheeling and transactions in a modern deregulated utility industry.

ROAD LAB V1.0 (Resource Optimizing, Access Delimited Laboratory) ${ }^{11}$ is a locally developed system prototype for remote access to the energy conversion laboratory at Penn State Harrisburg. The facility affords users the opportunity to operate laboratory machinery, and gather data in real-time from a remote location. A brief session and demonstration of ROAD LAB gives students an insight into the role and use of information system and technologies in power and energy systems' context.

The three-credit hour course does not include a formal laboratory session. It is however necessary to give students opportunities for hands-on sessions in an energy conversion laboratory. Students are expected to work in groups to set up and conduct experiments on determination of induction machine equivalent circuit parameters, performance characteristics, and speed control using PWM technology.

\section{Semester Project}

Students are required to conduct research on an assigned topic, write a paper, and present a report in a class session. The process includes critical review of peer-reviewed journal articles, and information from other sources with the goal of identifying the state of the art issues in the respective topics assigned. The following guidelines are offered to the students to assist them in the process:

I. Select research topic (or have a topic assigned by the instructor).

II. Conduct literature search on the topic.

III. Submit at least three relevant articles (IEEE Transactions, Magazines, etc.) along with your proposed research and paper outline for approval. (This is required no later than the third week of classes).

IV. Begin research; critically evaluate the information presented in the articles, and relate to research topic. What does it say about production, conversion, and use of energy? Identify what the current issues are, and the suggested future directions.

$\mathrm{V}$. Write paper. There is no length requirement for the paper. However, critical issues in most of the topics could be adequately addressed in 10-20 pages.

VI. Develop presentation outline (15 minutes, and 5 minutes for questions from the class).

Projects assigned to students in the last two sessions of the Energy System \& Conversion course include the following:

a. "The State of Pennsylvania - energy policies, implementation, funding, and organization." Address the following questions: What is the structure in place for energy management? Who or what shapes energy policies in the state? What is the most effective way to influence policy decisions? Comment on the electric and gas utility sector, the transportation industry, and energy conservation efforts. 
b. "The United Nations - energy policies, implementation, funding, and organization." Address the following questions: What is the structure in place for overseeing the energy sector?

Who or what shapes energy policies? Present a case study on successful implementation of a policy initiative.

c. "Electric utility deregulation in Pennsylvania - study of impact on energy use and consumer costs." What was it like before deregulation?

d. "Nuclear Energy; Environmental \& Safety Aspects - case study (US and Russia)."

e. "Energy Storage - case study (Transportation industry, politics, economics, etc.)"

f. "Design innovations for energy use reduction in home appliances - The Past and the Future." Chart improvements over the last decade, and propose design modification for an even better efficiency.

g. "The Uses of Solar Energy - Case studies focusing on Asia, Africa or Latin America (costs, reliability and impact on the community)."

Students work in groups of two on most of the topics assigned, and up to three on themes that are broad and require more extensive reading. The project accounts for $20 \%$ of the course grade.

\section{Learning Assessment}

Three in-class exams, including the final exam are given to assess cumulative learning as the semester progresses. In addition to this, homework problems are assigned as needed. Students are required to submit a formal project report on the research topic, and to present findings orally in class. Presentations are scheduled for 20 minutes during class periods over several weeks. They are expected to supplement concepts already learned during the semester. An oral as well as a written communication rubric is given to the student at the inception of the semester to enable them be more aware of what the instructor will evaluate. Between 0-10 points are awarded in individual categories that include: (a) organization of the presentation and report, (b) grammar, fluency and choice of words, (c) clarity and directness in exposition, (d) apparent technical and factual accuracy and grasp of the subject, etc. This also serves to ensure systematic and consistent scoring across all students.

\section{Conclusions}

The Energy Systems and Conversion course is designed to fill a critical gap in the electrical engineering curriculum. It covers the foundational theory of the most widely used electrical energy conversion devices, and guides students to explore various energy sources, conversion technologies, and highlights economic, environmental, sustainability, health and safety, social, and political issues in energy use.

Students make a vital connection between materials learned in lectures, and practice in the energy industry through field trips to a power plant whenever possible. This also takes place through service-learning opportunity as students host grade school pupils and educate them on energy issues. 
The learning environment is enhanced through collaborative learning opportunities; students work in teams on semester projects, and participate in frequent group discussions on news-maker energy topics of the week. Through carefully selected topics, the semester projects enable students to reach into wide-ranging subject areas such as, economics, environment, ethics, health and safety, sustainability, social, politics, among others.

Simulation is used to clarify difficult concepts in modeling and projection which are not practical to demonstrate in the laboratory, while hands-on sessions in the energy conversion laboratory environment offers avenues to validate concepts covered in lectures.

Technology-enhanced methods of presentation make it possible to share a large body of material with students. Use of video, computer animations, in-class access to online government databases, journal article texts, and more help clarify topics discussed and provide a better appreciation of the wealth of resources available on energy systems.

\section{References}

1 Bohmann Leonard J., et-al, “The New Energy Systems Course at Michigan Tech." $29^{\text {th }}$ ASEE/IEEE Frontiers in Education Conference, November 10 - 13, 1999. San Juan, Puerto Rico. 11b6-24.

2 Fitzgerald A, Kingsley C, "Electric Machinery," $6^{\text {th }}$ edition, McGraw-Hill Publishing Company.

3 Sen P. C., "Principles of Electric Machines and Power Electronics," $2^{\text {nd }}$ edition, John Wiley and Sons, 1997.

4 Kraushaar Jack J., Ristinen Robert A., "Energy and Problems of a Technical Society" 2nd edition, John Wiley, 1993.

5 Dorf Richard C., "Technology, Humans, and Society - Towards a Sustainable World." Academic Press. 2001.

6 Bregman R, Knapp R., Takahashi P, "Design Considerations for Ocean Energy Resource Systems." Proceedings of the 1995 MTS/IEEE Oceans Conference. Part 1 (of 3), Oct 9-12 1995, San Diego, CA, USA, p 1084-1091.

7 Braun G, McCluer H, "Geothermal Power Generation in United States." Proceedings of the IEEE, v 81, $\mathrm{n}$ 3, Mar, 1993, p 434-448.

8 Energy Citations Database (ECD), http://www.osti.gov/energycitations/

9 MATLAB 6.5, The MathWorks, Inc., Natick, MA.

10 PowerWorld Simulator V8.0 (Educational), PowerWorld Corporation, Urbana, IL.

11 Idowu, P. "Development of a prototype resource optimizing, access delimited (ROAD) laboratory." Proceedings, IEEE Power Engineering Society Winter Meeting 2002, Page(s): 1405 -1409 vol.2.

\section{Biography}

Peter Idowu obtained his Ph.D. degree from the University of Toledo, Ohio in 1989. He is a registered professional engineer in the state of Ohio and is currently an associate professor of electrical engineering at The Pennsylvania State University - Harrisburg, PA. 
Table 1. Schedule of course topics and class activities

$$
\text { TOPICS }
$$

Introduction to the course: Semester projects - topics and schedules. Energy Basics: Forms of energy; Sources of energy; Energy consumption \& GNP; Geology; Mining, Reserves. Energy Databases. Statistical models for projecting energy use trends.

Fossil Fuels \& Heat Engines: Energy content of fuels; Heat engines; Generation of electricity; Heat pumps. Efficiency of practical heat engines.

Nuclear Energy, Environmental \& Safety Issues: Nuclear reactions; Uranium resources; Nuclear reactors; Radioactive emissions \& Wastes.

Solar Energy: Solar energy basics; Heat transfer; Collector system; Thermal-electric \& Photovoltaic systems. Conversion efficiency of practical systems.

Renewable Energy Sources: Hydroelectric power; Wind power; OTEC, Tide, Wave energy, Geothermal energy: Conversion efficiency of practical systems. LEARNING ASSESSMENT \# 1

Renewable Energy Sources: Environmental and social impacts. Energy Storage: Pumped hydro system; Fuel cell (hydrogen); Batteries; Flywheels; Compressed air. Optimal Economic Load Dispatch in an interconnected power system.

Integrated Energy Systems: Case studies. Sustainable engineering and business practices.

LAB\#1 - MATLAB ${ }^{\mathbb{C}}$ simulation of wind energy conversion systems.

Magnetic Circuits: - I-H \& B-H curves, Equivalent circuits, Inductance, Power Transformers.

Magnetic Circuits - Three-phase transformer connection - American Standard.

Electromechanical Energy Conversion - Principles

LAB\#2 - MATLAB ${ }^{\mathcal{C}}$ simulation of electromechanical systems.

Poly-phase Induction Machines - Operation, Equivalent circuit model, No-load \& Blocked-rotor tests.

Performance characteristics. NEMA Standard design B, C \& D.

Synchronous Machines - Construction, Equivalent circuit model, Operation, Power \& Torque angle

characteristics. LEARNING ASSESSMENT \# 2

Synchronous Machines - Power factor control; Special synchronous motors.

LAB\#3 - Induction motor (equivalent circuit parameters)

DC Machines: Motors \& Generators). Service Learning - Student-community interaction (open house for elementary school pupils) - Energy exploitation and use.

Speed Control - AC and DC machines

$\mathrm{LAB} \# 4$ - Induction motor (performance characteristics and speed control)

Presentations: LEARNING ASSESSMENT

Overview of Power Transmission \& Distribution: PowerWorld ${ }^{\mathbb{C}}$ Simulator for interconnected Power System.

Power System Computations. System operation in a deregulated environment.

LEARNING ASSESSMENT \# 3 